\title{
Esporos de Clostridium botulinum em mel comercializado no Estado de São Paulo e em outros Estados brasileiros
}

\author{
Clostridium botulinum spores in honey commercialized in São Paulo \\ and other Brazilian states
}

\author{
Adriana Valim Ferreira Ragazani ${ }^{{ }^{*}}$ Ruben Pablo Schoken-Iturrino ${ }^{\mathrm{I}}$ \\ Gisela Rojas Garcia ${ }^{I}$ Tammy Priscilla Chioda DelfinoI \\ Maria Luiza Poiatti ${ }^{I}$ Silvina Pelicano Berchielli ${ }^{\mathrm{I}}$
}

\section{RESUMO}

O botulismo infantil tem afetado crianças abaixo de um ano de idade em várias regiões do mundo, e o mel tem sido identificado como uma das mais importantes fontes de intoxicação alimentar. Apesar disso, há dados escassos sobre o botulismo entre crianças no Brasil, especialmente no tipo de alimento comercial mais implicado nesta patologia. Este estudo pretendeu investigar a presença de esporos de Clostridium botulinum em mel comercializado no Brasil. Cem amostras de mel comercializado em seis diferentes Estados brasileiros (SP, $M G, G O, C E, M T, S C$ ) foram pesquisados para a presença de esporos de Clostridium botulinum, usando o choque térmico, seguido pela inoculação em caldo Cooked Meat Medium $\left(\right.$ DIFCO $\left.{ }^{\circledR}\right)$ e incubado em condições anaeróbias. As culturas positivas foram analisadas através de esfregaços corados pelo Gram e semeadas em placas de Reinforced Clostrideo Agar $\left(D I F C O^{\circledR}\right)$ e placas de Sulfito Polimixina Sulfadiazina -SPS $\left(\right.$ DIFCO $\left.{ }^{\circledR}\right)$, as quais foram incubadas em condições anaeróbicas para obter colônias desta bactéria. As colônias positivas foram submetidas a teste de toxicidade através da inoculação em camundongos susceptíveis e caracterização bioquímica. Foram encontradas colônias de Clostridium botulinum que produzem toxinas ativas em $7 \%$ das amostras de mel comercial, realçando a relevância deste microrganismo para a saúde pública devido ao alto risco potencial de o mel comercializado nestas regiões brasileiras causar o botulismo infantil, especialmente em crianças abaixo de um ano de idade.

Palavras-chave: Clostridium botulinum, botulismo infantil, esporulados.

\section{ABSTRACT}

Infant botulism has been affecting children under one year of age in several regions of the world and honey has been identified as one of the most important source of this food borne disease. Despite this, there are scarce data about botulism among children in Brazil, specially the type commercial food most implicated in this pathology. This study aimed at investigating the presence of spores of Clostridium botulinum in honey commercialized in Brazil. One hundred of honey samples commercialized in six different Brazilin states (SP, $M G, G O, C E, M T, S C)$ were searched for the presence of spores of Clostridium botulinum, using thermal shock followed by the inoculation in Cooked Meat Medium (DIFCO ${ }^{\circledR}$ ) and incubation in anaerobic conditions. The positives cultures were analyzed by Gram stain and seeded in Reinforced Clostrideo Agar $\left(D_{F C O}{ }^{\circledR}\right)$ and Sulfito Polimixina Sulfadiazina -SPS $\left(\right.$ DIFCO $\left.^{\circledR}\right)$ plates, which were incubated in anaerobic conditions in order to pick up the colonies of this bacteria. The positive colonies were submitted to toxicity test by inoculation in susceptible mice and to biochemical characterization. Clostridium botulinum colonies producing actively toxins were detected in $7 \%$ of the commercial honey samples, highlighting the relevance of this microorganism for public health due to the high potential risk of honey commercialized in these Brazilian regions to cause Infant Botulism, specially in children under one-year old.

Key words: Clostridium botulinum, infant botulism, sporulates

\section{INTRODUÇÃO}

Botulismo é um tipo severo de intoxicação alimentar causado pela ingestão de alimentos contendo uma potente neurotoxina formada durante $o$ crescimento do Clostridium botulinum, cujos esporos estão freqüentemente distribuídos na natureza (SOLOMON \& LILLY, 2001). A origem desses esporos é desconhecida no botulismo infantil, mas o mel tem sido identificado como possível fonte de contaminação (ARNON et al., 1981). Dez categorias de alimento infantil, incluindo mel e xarope de milho, foram

IDepartamento de Patologia Veterinária, Laboratório de Microbiologia Agropecuária, Universidade Estadual Paulista (UNESP), Faculdade de Ciências Agrárias e Veterinárias de Jaboticabal. Rod. Carlos Tonanni, Km 5, 14887-000, Jaboticabal, SP, Brasil. Email: ragazani@fcav.unesp.br.*Autor para correspondência. 
analisadas para a presença de esporos de $\boldsymbol{C}$. botulinum, sendo que, dentre as 100 amostras de mel, duas apresentaram-se positivas para esta bactéria e 40 amostras de xarope de milho continham esporos de $\boldsymbol{C}$. botulinum (KAUTTER et al., 1982).

Crianças menores de um ano de idade são mais susceptíveis ao desenvolvimento da doença devido à imaturidade da flora intestinal que, ao ingerir alimento contendo esporos, permite a germinação, multiplicação e produção de neurotoxina botulínica no intestino infantil (ARNON et al., 1981).

A pesquisa do grupo de bactérias esporuladas presentes no mel reveste-se de importância desde que, em 1976, o botulismo infantil foi identificado, nos EUA, como uma entidade clínica resultante da colonização intestinal e da produção de toxina pelo Clostridium botulinum, descritos por PICKETT et al. (1976) e ARNON et al. (1977). Mais tarde, correlacionouse a ingestão de mel com surtos ocorridos com crianças menores de um ano de idade, conforme ARNON et al. (1981).

A presente investigação objetivou avaliar a qualidade microbiológica do mel comercializado em seis Estados brasileiros (São Paulo, Mato Grosso, Goiás, Ceará, Minas Gerais e Santa Catarina), verificando a presença de esporos de Clostridium botulinum neste produto alimentar, sendo este um risco inerente à saúde infantil.

\section{MATERIAL E MÉTODOS}

Foram obtidas 100 amostras de mel comercializadas por ambulantes, mercados e feiras livres, em seis Estados do Brasil (São Paulo, Mato Grosso, Goiás, Minas Gerais, Ceará, Santa Catarina). As análises foram realizadas no Laboratório de Microbiologia da Faculdade de Ciências Agrárias e Veterinárias- Campus Jaboticabal - SP (UNESP), no período de janeiro de 2002 a julho de 2003.

Após a identificação, foram pesados 25 gramas de cada amostra e diluídos em $225 \mathrm{~mL}$ de água peptonada esterilizada (0,1\%). A partir desta diluição, foram transferidas doses de $1 \mathrm{~mL}$ para tubos de rosca contendo 9mL do meio CMM (Cooked Meat Medium - DIFCO ${ }^{\circledR}$ ), ajustando o pH para 7,2, segundo SCHOCKEN-ITURRINO et al. (1999). Os tubos de CMM inoculados foram submetidos a choque térmico a 80$82^{\circ} \mathrm{C}$, por $10 \mathrm{~min}$, resfriando-os a $30^{\circ} \mathrm{C}$ em água com gelo e incubados em anaerobiose a $37^{\circ} \mathrm{C}$, por um período de 5 a 10 dias. Observando o crescimento bacteriano, as amostras foram submetidas a esfregaços corados pelo método de Gram, visualizando bastonetes Gram positivos com esporos ovais subterminais característicos do gênero Clostridium, como descrito por HOLT et al. (1994). Estas amostras foram semeadas em duas placas de Petri estéreis contendo uma o meio Ágar Reiforced Clostrideo (RFCA - DIFCO ${ }^{\circledR}$ ) e a outra Ágar Sulfito Polimixina Sulfadiazina (SPS - DIFCO ${ }^{\circledR}$ ). As placas foram incubadas em anaerobiose, por 2448h, com o sistema Gás-Pak ${ }^{\circledR}$ (SEGNER et al., 1971).

As colônias que apresentaram características típicas de Clostridium sp em ágar RFCA (SMITH, 1977) e as colônias negras, características de Clostrídios sulfito-redutores em ágar SPS, foram transferidas para tubos de BHI (contendo caldo infusão de cérebro e coração - DIFCO ${ }^{\circledR}$ ), acrescidos de $0,5 \%$ de cloridreto de cisteína e incubados a $37^{\circ} \mathrm{C}$, por 24 a 48h. Após esse período, foram realizados novos esfregaços corados pelo método de Gram e teste de catalase, para diferenciar o gênero Clostridium sp de Bacillus sp. Posteriormente, foram realizados os seguintes testes para caracterização bioquímica: fermentação de carboidratos (glicose, maltose, lactose, sacarose), salicina, atividade da lecitinase, urease, proteólise, produção de indol, teste da motilidade, hidrólise da gelatina, redução de nitrato e hemólise (HOLT et al., 1994; VANDERZANT \& SPLITTSTOESSER, 1992).

Para detecção da presença de toxina botulínica, foram utilizados 5mL dos tubos de CMM, que obtiveram crescimento, filtrados em membrana Milipore $(0,45 \mu \mathrm{m})$, e inoculados $0,5 \mathrm{~mL}$ do filtrado intraperitonealmente em pares de camundongos albinos. Da mesma forma, como controle, foi também inoculada uma alíquota da amostra aquecida a $100^{\circ} \mathrm{C}$, durante 15 minutos, sofrendo a desnaturação, descartando, desse modo, a ocorrência de mortes dos camundongos por causa da presença de outras substâncias (SMITH, 1977). Os animais foram observados por um período de 5 a 10 dias, para verificar a presença de sinais como: dificuldade respiratória e de locomoção, evidenciadas pela formação de "cintura de vespa”, e pela morte dos camundongos por paralisia flácida, com exceção dos animais que receberam a alíquota desnaturada (controle) (HUHTANEN et al., 1981).

\section{RESULTADOS E DISCUSSÃO}

Os resultados do presente estudo demonstraram a presença de bactérias esporuladas em 61\% das amostras. Dentre estas, 39\% apresentaram bactérias sulfito-redutoras, sendo que $11 \%$ eram do gênero Clostridium e 28\% do gênero Bacillus. Dentre os 11\% isolados de Clostrídios, 7\% foram confirmados como sendo Clostridium botulinum. 
A incidência de esporos de $\boldsymbol{C}$. botulinum em mel tem sido estimada em diversos estudos SUGIYAMA et al. (1978), usando o método de diálise em 241 amostras de mel, nos EUA, relataram a presença de esporos de $\boldsymbol{C}$. botulinum em 18 amostras originadas dos Estados de Califórnia, Flórida, Iowa, Michigan, Minnesota, Nebrasca, Tenessee, Texas e Washington. Em experimento realizado por MIDURA et al. (1979), foram isoladas nove amostras de $\boldsymbol{C}$. botulinum entre 90 amostras de mel analisadas. Dentre essas, seis amostras tinham sido fornecidas a bebês, que desenvolveram a doença.

WILCKE et al. (1980) avaliaram a microbiota fecal de quatro crianças com botulismo infantil, revelando a presença de Clostridium botulinum.

Resultados semelhantes aos do presente estudo foram demonstrados por SCHOCKENITURRINO et al. (1999), analisando 85 amostras de mel e identificando o crescimento bacteriano de Clostridium sp em 27,06\% das amostras avaliadas. Dentre estas, seis evidenciaram a presença de $\boldsymbol{C}$. botulinum, sendo duas do tipo A, uma do tipo B e três do tipo D. Fato similar foi demonstrado por CENTORBI et al. (1994), na Argentina, em 42 amostras de mel de diferentes apiários, as quais revelaram a presença de esporos de $\boldsymbol{C}$. botulinum em 33,3\% (14) das amostras, porém somente uma amostra ocasionou a morte de camundongos. Dados relatados por CRISEO et al. (1994), analisando 66 amostras de mel, na Itália, entre o período de 1990 a 1991, demonstraram a presença de esporos de Clostridium em 23\% dessas amostras, sendo duas amostras positivas para $\boldsymbol{C}$. botulinum. Diferentemente do resultado obtido por DELMAS et al. (1994), quando avaliaram 116 amostras de mel, na França, nenhuma amostra foi positiva para $\boldsymbol{C}$. botulinum. Em outro estudo realizado por KAUTTER et al. (1982), avaliando 10 categorias de alimentos para crianças, foi demonstrado que, dentre 100 amostras de mel, 2\% apresentaram esporos de $\boldsymbol{C}$. botulinum. Na Itália, FARRIS et al. (1981), avaliando a microflora de 49 amostras de mel, demonstraram esporos de bactérias anaeróbias em 10,2\% das amostras.

Estudo realizado por RALL et al. (2001) em amostras de mel comercializadas em São Paulo revelaram ausência de esporos de Clostridium botulinum. Em outro estudo realizado por RALL et al. (2003), analisando 100 amostras de mel do Estado de São Paulo, relataram a presença de esporos de $\boldsymbol{C}$. botulinum em três amostras. Contudo, na presente investigação, os resultados obtidos, inclusive com a identificação de esporos deste patógeno, reforçam a importância deste achado para a saúde pública.

\section{CONCLUSÃO}

O botulismo infantil é uma forma especial de doença de origem alimentar, a qual afeta quase exclusivamente as crianças com idade inferior a um ano. O mel é a única fonte registrada de alimento veiculador do agente causador do botulismo infantil, o Clostridium botulinum.

Através dos resultados obtidos pela presente investigação, pode-se concluir que o mel comercializado em seis Estados brasileiros (SP, MG, MT, GO, CE, SC), revelando a presença de percentagem significativa de Clostridium botulinum (7\%), não deve ser incluído na dieta de crianças menores de um ano de idade, causando um risco a saúde pública. O Botulismo continua a ser um problema de saúde pública de todo o mundo; por este fato, são necessárias maiores investigações não somente na detecção de Clostridium botulinum no mel, mas também na de outros microrganismos e $\mathrm{n}$ forma como são incorporados nesse alimento.

\section{AGRADECIMENTO}

À Coordenadoria de Aperfeiçoamento de Pessoal de Nível Superior (CAPES), pelo suporte financeiro.

\section{REFERÊNCIAS}

ARNON, S.S. et al. Infant botulism: epidemiological, clinical and laboratory aspects. Journal American Medical Association, v.237, p.1946-1951, 1977.

ARNON, S.S. et al. Infant botulism: epidemiology and relation to sudden infant death syndrome. Epidemiologic Review, v.3, p.45-66, 1981.

CENTORBI, O.P. et al. Análisis bacteriológico e investigación de esporos de Clostridium botulinum em mieles. Revista Argentina Microbiologia, v.26, p.96-100, 1994.

CRISEO, G. et al. Caracterizzazione microbiologica di miele di produzione siciliana com particolare riferimento a microrganismi patogeni e biodeteriogeni. L'Igiene Moderna, v.102, n.3, p.315-328, 1994.

DELMAS, C. et al. Survey of honey for Clostridium botulinum spores in eastern. Food Microbiology, v.11, p.515-518, 1994.

FARRIS,G. A. et al. Caratterizzazione microbiológica dei mieli della Sardegna. Tecnologie Alimentarie, v.4, p.18-23, 1981.

HOLT, J.G. et al. Bergey's: manual of determinative bacteriology. 9.ed. Baltimore: Williams \& Williams, 1994. p.186-187.

HUHTANEN, C.N. et al. Incidence and origin of Clostridium botulinum spores in honey. Journal Food Protection, v.44, n.11, p.812-814, 1981.

KAUTTER, D.A. et al. Clostridium botulinum spores in Infant foods: a survey. Journal Food Protection, v.45, n.11, p.10281029, 1982.

Ciência Rural, v.38, n.2, mar-abr, 2008. 
MIDURA, T.F. et al. Isolation of Clostridium botulinum from honey. Journal of Clinical Microbiology, v.9, n.2, p.282283, 1979.

PICKETT, J. et al. Syndrome of botulism in infancy: clinical and eletrophysiologic study. New England Journal of Medicine, v.295, p.770-772, 1976.

RALL, V.L.M. et al. Incidência de esporos de Clostridium botulinum e análise da qualidade microbiológica do mel no estado de São Paulo. In: CONGRESSO BRASILEIRO DE MICROBIOlOGIA, 21., 2001, Foz do Iguaçu, PR. Anais... Foz do Iguaçu: Sociedade Brasileira de Microbiologia, 2001. p.403.

RALL, V.L.M. et al. Honey consumption in the state of São Paulo: a risk to human health? Anaerobe, v.9, p.299-303, 2003.

SCHOCKEN-ITURRINO, R.P., et al. Study of presence of the Clostridium botulinum in honey in Brazil. FEMS Imunology and Medical Microbiolgy, v.24, p.379-382, 1999.

SEGNER, W.P. et al. Minimal growth temperature, sodium chloride tolerance, $\mathrm{pH}$ sensitivy and toxin, production of marine and terrestrial strains of Clostridium botulinum type C. Applied Microbiology, v.22, p.1025-1029, 1971.

SMITH, L.S. Botulism the organism, its toxins, the disease. Springfield: Charles Thomas, 1977. 236p.

SOLOMON, H.M.; LILLY, T. Jr. Clostridium botulinum Bacteriological analytical manual (8.ed.). (2001). Chapter 17. Disponível em: http://vmcfsan.fda.gov/ ebam/bamtoc.html.

SUGIYAMA, H. et al. Number of Clostridium botulinum spores in honey. Journal Food Protection, v.41, n.11, p.848-850, 1978.

VANDERZANT, C.; SPLITTSTOESSER, D.F. Compendium of methods for the microbiological examination of food. 3.ed. Washington: American Public Health Association, 1992. 1219p.

WILCKE, B.M.W. et al. Quantative evidence of intestinal colonization by Clostridium botulinum in four cases of infant botulism. Journal Infection Diseases, v.141, p.419-423, 1980 . 